\title{
Sustainability Analysis of Low Temperature Solar-Driven Kalina Power Plant Using Emergy Concept
}

\author{
Ehsan Rafat, Mojtaba Babaelahi*, Ehsan Mofidipour \\ Department of Mechanical Engineering, University of Qom, Qom, Iran, P.O. Box 3716146611. \\ E-mail: *mbabaelahi@gmail.com, m.babaelahi@qom.ac.ir
}

Received 12 April 2019, Revised 24 July 2019, Accepted 03 August 2019

\begin{abstract}
Selection, design, and optimization of the energy system with the efficient method is one the major problem in recent years. The combined Emergy-Exergy-Economic-Environmental analysis is one of these new methods selected for the analysis and optimization of energy systems. In this paper, the low temperature small solar-driven Kalina power plant is selected for distributed power generation in Qom city. The analysis procedure based on Emergy, Exergy, Economic and Environmental concepts is performed in two general steps. In the first step, the thermodynamic and exergy analysis is performed and the required thermodynamic and exergetic parameters are determined. For the calculation of emergy for different component and mass flow, in the second step, the weight and price of all equipment are evaluated and the emergy analysis is performed. Based on this analysis the emergy evaluation parameters such as monetary and ecological performance are presented and based on these parameters, the most destructive equipment is selected and a suitable procedure for improvement in the considered system is presented. In the final step, the exergy and emergy parameters in the proposed solar Kalina cycle are compared with some renewable and fossil power plant and this comparison show that the proposed cycle has suitable characteristics.
\end{abstract}

Keywords: Kalina; solar; power; exergy; emergy; monetary; ecological.

\section{Introduction}

With overgrowing concern over the impact of fossil fuels on the environment, finding the available alternative to these sources of energy is one of the main goals of humanity in recent decades. Within all different sources of energy, solar energy, in terms of economic and availability, seems to be the best possible choice. Over the past decade, the technologies related to using low-temperature heat sources for generating electricity have widely increased and improved. One of the thermodynamic cycles used to generate electricity from low-temperature sources is the Kalina cycle. This cycle is firstly proposed in 1982 by Kalina [1] which uses a mixture of ammonia and water as the working fluid which has lower boiling temperature compared to other conventional working fluids like water so this cycle can be used to generate electricity from low-temperature heat sources.

Rogdakis and Antonopoulos [2] showed that for the same working condition, Kalina cycle performs $20 \%$ better in term of efficiency compared to the conventional Rankin cycle. Hettiarachchi et al. [3] have compared the performance of the Kalina cycle with an organic Rankin cycle for a lowtemperature geothermal heat source and examined the impact of the ammonia-water concentration and inlet pressure of turbine on the efficiency. Murugan and Subbarao [4] proposed a combination of Rankin and Kalina cycle to reduce energy loss and improve the efficiency of the cycle and also performed energy and exergy analysis on the proposed cycle. Various researches have been directed on integrating solar energy with the Kalina cycle. Lolos and Rogdakis [5] investigated a Kalina cycle in which the main heat source is maintained using flat solar collectors. The effects of ammonia mass fraction at the turbine inlet on the performance of the cycle is examined. Sun et al. [6] investigated a solar assisted Kalina cycle with an auxiliary superheater and discussed the effect of system parameters for high-performance power generation. Ganesh and Srinivas [7] studied a low temperature solar parabolic trough collector Kalina cycle and performed energy analysis and investigated effects of different thermodynamic parameters in order to optimize the heat recovery from collectors and maximize the generated power and efficiency as well. Wang et al. [8] considered a solar-driven Kalina cycle with thermal storage and studied the effects of pressure and temperature in the inlet of the turbine of the performance of cycle over a period of time. Peng et al. [9] examined a novel solar-driven triple cycle including a gas turbine Bryton, steam Ranking and Kalina cycle to make the possibility of generating power during low insolation periods. the efficiency of the recommended cycle calculated to be $22.7 \%$. Modi and Haglind [10] investigated a Kalina cycle with a central solar receiver and direct steam generator and compared the performance of the cycle in terms of exergy efficiency with Rankine cycle. Sun et al. [11] performed energy and exergy analysis on Kalina cycle system 11 with a flat collector solar system and an auxiliary superheater. An optimization is performed using the monthly solar radiation in Kumejima Island of Japan. Zare et al. [12] applied exergoeconomic analysis to a combination of Kalina cycle and Gas TurbineModular Helium Reactor where the waste heat from the top cycle is recovered by Kalina cycle. The results show the efficiency is $8.2 \%$ higher and the cost is $8.8 \%$ lower compared to the situation without waste heat recovery by the Kalina cycle. Rodríguez et al [13] performed thermo- 
economic analysis on an organic Rankin cycle and a Kalina cycle to generate power from the geothermal heat source. Fifteen different working fluid for ORC and three ammoniawater compositions have been evaluated for the Kalina cycle. It was shown that the Kalina cycle has a levelized cost of electricity of $0.18 € / \mathrm{kW}$ and also produced $18 \%$ more electricity. Boyaghchi and Sabaghian [14] performed exergoeconomic analysis on a solar driven Kalina cycle and studied the effect of different parameters on the exergetic efficiency and unit cost of the electricity of the plant.

Evaluating the economic and environmental performance of energy systems is one of the challenges in improving and optimizing the performance of these systems. Two powerful and common tools to cope with this problem are Exergoeconomic and exergoenvironmental analyses. In these analyses, monetary and ecological values (generally in the unit of USD and millipoints) are assigned to streams in the exergy balance of each component. However, the results of these analyses have different scale and dimensions as they are generally given in units of $\$ / G J$ and $\mathrm{mPts} / \mathrm{Gj}$ which makes it complex to evaluate the results and to determine the optimum point of the system. One alternative to address this issue is using emergy as an input value instead of exergy based values.

In the presented study, we carried out a thermodynamic model of a solar driven Kalina cycle at first, then performed an exergy analysis on the proposed cycle. The emergy analysis has been performed in order to find the performance of the cycle in terms of Transformity and sustainability index. In the end, the EMergoeconomic and EMergoenvironmental analysis have been done to find prior nominees for optimization of the ecological and economic performance of the cycle. The emergy concept is firstly presented by H.T. Odum in the early 1980s [15]. All of the energy used, directly or indirectly through conversion processes, to make a product or service can be evaluated using emergy method. In this method, all of the system's inputs (energy, mass, service, etc.) are transformed to an equivalent unit called solar energy joule. Brown and Ulgiati [16] used this method to evaluate the environmental performance of six different power plant which showed the renewable technology has better performance in term of sustainability compared to fossil fuel power plants. Furthermore, other works have been done by integrating the emergy concept with Life Cycle Assessment and evaluated the performance of different power plants [17-19]. Aghbashlo and Rosen [20] integrated emergy concept with conventional exergoeconomic and exergoenvironmental analysis by transforming input values in these analyses to emergy unit to improve the results and as a case study investigated a combined heat and power cogeneration system using this method and compared the results with conventional exergoeconomic and exergoenvironmental analysis. For the sake of simplicity, we will refer to these analyses as EMergoeconomic and EMergoenvironemntal analysis.

In this paper, the determination of a destructive and improper component in a small solar-driven Kalina cycle are considered, and the combined emergy, exergy, economic and environmental analysis is used for this purpose. The selection of mail destructive component in this paper is performed based on the flowing procedure: in the first step, the thermodynamic analysis of the cycle is performed, and the thermodynamic parameters of the cycle and thermal efficiency are determined. In the next step, the exergy analysis is performed, and exergetic parameters are evaluated. In the third step, the mass and purchase cost of each component are calculated. In the fourth step the emergy balance is performed, the emergy values for all equipment and flows are calculated and the emergy evaluation parameters are examined. In the final step, the analysis of emergy parameters for the different component are performed and suitable approach for reduction of improper effects are proposed.

\section{Modeling}

\subsection{Description of Proposed Cycle}

The flow diagram of the solar driven Kalina cycle is illustrated in Figure 1. The heated fluid coming from solar collectors (14) exchanges its heat to the working fluid, mixture of ammonia and water, in superheater and evaporator. The superheated ammonia-water mixture (1) with an ammonia concentration of 0.95 become expanded in the mixture turbine to generate power (2). The exiting flow will be mixed with the weak ammonia mixture coming from the separator (13). The mixture loses its heat in a lowtemperature regenerator and becomes condensed in the condenser (3-4-5). It is considered that the outlet flow of condenser is saturated liquid. Then the working fluid will be pumped to gain heat in low and high-temperature regenerators (6-7-8). The liquid becomes evaporated in the evaporator and then goes to the separator to make a rich ammonia-water vapor which goes to superheater to be superheated (9-10). To present a thermodynamic model of the proposed cycle the following assumptions are made:

- The ambient temperature and pressure are $25^{\circ} \mathrm{c}$ and 100 $\mathrm{kPa}$.

Pinch point (PP) and approach point (AP) of the boiler are $5^{\circ} \mathrm{C}$ and $10^{\circ} \mathrm{C}$ respectively.

The isentropic efficiency of pump and turbine is $0.75 \%$.

The mechanical efficiency of the pump and the turbine is $96 \%$.

- The leaving working fluid in the condenser is assumed to be saturated liquid.

- Calculations are performed in steady state conditions.

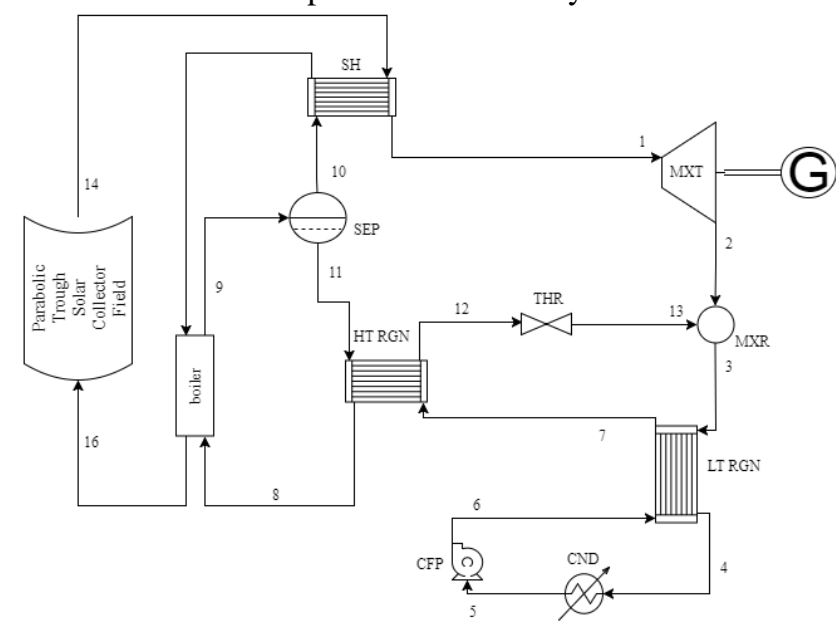

Figure 1. Schematic view of the solar-driven Kalina cycle.

\subsection{Thermodynamic Modeling \\ 2.2.1 Energy Balance Equation}

In order thermodynamic modelling of the proposed cycle, a steady state model of the plant has been created in MATLAB software and REFPROP code has been used to find the enthalpy and the entropy of different streams. The following equations are used to model different components of the plant. 
Mixture Turbine:

$W_{t}=m_{1}\left(h_{1}-h_{2}\right) \eta_{m . t} \eta_{g e}$

Condensate Feed Pump:

$W_{P}=\frac{m_{5}\left(h_{6}-h_{5}\right)}{\eta_{m . P}}$

Separator:

$m_{9} h_{9}=m_{10} h_{10}+\left(1-m_{10}\right) h_{11}$

Condenser:

$Q_{C N D}=m_{5}\left(h_{5}-h_{4}\right)$

Superheater:

$Q_{S H}=m_{1}\left(h_{1}-h_{10}\right)$

Low-Temperature Regenerator:

$m_{3} h_{3}+m_{6} h_{6}=m_{4} h_{4}+m_{7} h_{7}$

High-Temperature Regenerator:

$m_{7} h_{7}+m_{11} h_{11}=m_{8} h_{8}+m_{12} h_{12}$

Boiler:

$Q_{\text {boiler }}=m_{9}\left(h_{9}-h_{8}\right)$

The outlet temperature of the solar collector and the input temperature of the boiler can be calculated as below:

$T_{14}=T_{1}+T T D_{S H}$

$T_{8}=T_{b p}-A P$

Where TTD_SH is the terminal temperature difference at super heater and T_bp is the bubble point temperature at boiler pressure. The outlet temperature at the hot side of the boiler can be calculated as below:

$T_{16}=T_{b p}+P P$

Net output power and cycle efficiency of the proposed system can be determined from the following equations:

$W_{\text {net }}=\left(W_{t}-W_{p}\right)$

$\eta_{K C}=\frac{W_{\text {net }}}{Q_{\text {boiler }}+Q_{S H}} \times 100$

In order to calculate the length and number of parabolic trough collectors, the following concepts can be used. The relation between width and rim angle of the collector to its focal length can be written as Eq. (14):

$$
f=\frac{W}{4 \times \tan \left(0.5 \phi_{\text {rim }}\right)}
$$

In the above equation, width $(\mathrm{W})$ and rim angle $\left(\phi_{\text {rim }}\right)$ of the collector assumed to be $3 \mathrm{~m}$ and $80^{\circ}$ respectively. The arc length of the collector's reflector is calculated from the Eq. (15):

$$
\begin{aligned}
L_{\operatorname{arc}}=2 f\left[\sec \left(\frac{\phi}{2}\right) \tan \left(\frac{\phi}{2}\right)\right. \\
+\ln \left(\sec \left(\frac{\phi}{2}\right)\right. \\
\left.\left.+\tan \left(\frac{\phi}{2}\right)\right)\right]
\end{aligned}
$$

The mass flow rate of the heat transfer fluid used as a working fluid in the solar collectors is determined with Eq. (16):

$$
m_{h}=m_{14}=\frac{m_{8}\left(h_{9}-h_{8}\right)+m_{10}\left(h_{1}-h_{10}\right)}{C_{p h}\left(T_{14}-T_{16}\right)}
$$

In the prosed solar system, there are parallel sections of collectors, thus the mass flow in each parallel section can be calculated by dividing the total mass flow $\left(m_{h}\right)$ to the number of parallel sections $\left(\mathrm{n}_{\mathrm{ps}}\right)$ :

$$
m_{h . p s}=\frac{m_{h}}{n_{p s}}
$$

By the above variables, the length of each collector can be expressed with Eq. (18):

$$
L=\frac{m_{14} C_{p h}\left(T_{14}-T_{16}\right)}{\eta_{c} I_{b} W n_{p s}}
$$

In which $\eta_{c}$ is the efficiency of the parabolic trough collector and is determined from the following correlation:

$$
\eta_{c}=0.642-0.441\left(\frac{T_{f i}-T_{a}}{I_{b}}\right)
$$

Based on the above-calculated parameter, the total collector's area is calculated as below:

$$
A_{\text {c tot }}=n_{p s} W L
$$

\subsubsection{Exergy Balance Equation}

The exergy of a system is the maximum useful work possible during a process. The exergy is consisting of four different forms including potential, kinetic, physical, and chemical. In this work, the potential and kinetic exergy are neglected due to their deniable values compared to the other two forms. The physical and chemical exergy of each stream is calculated from the following equations:

$$
\begin{aligned}
& \dot{E}_{i}^{P H}=\dot{M}\left(h_{i}-h_{0}-T_{0}\left(s_{i}-s_{0}\right)\right) \\
& E_{i}^{C H}=\dot{M}\left(\Sigma x_{k} \bar{e}_{k}^{C H}+\bar{R} T_{0} \Sigma x_{k} \ln x_{k}\right)
\end{aligned}
$$

Where $\mathrm{T}_{0}$ is the reference temperature, $\mathrm{x}_{\mathrm{k}}$ is the mole fraction gas and $\bar{e}_{\mathrm{k}}^{\mathrm{CH}}$ represents standard molar chemical exergy of gas. Total exergy of a stream is the summation of physical and chemical exergy of that stream:

$$
\dot{E}=\dot{E}^{P H}+\dot{E}^{C H}
$$

The thermal exergy of heat flows can be calculated as

\begin{tabular}{|c|c|c|}
\hline Components & Exergy Rate Balance & $\begin{array}{l}\text { Exergy } \\
\text { Efficiency }\end{array}$ \\
\hline Boiler & $\begin{array}{l}E_{9}+E_{16}+E_{D} \\
=E_{8}+E_{15}\end{array}$ & $\frac{E_{9}-E_{8}}{E_{15}-E_{16}}$ \\
\hline Separator & $E_{10}+E_{11}+E_{D}=E_{9}$ & $\frac{E_{10}+E_{11}}{E_{9}}$ \\
\hline Super heater & $\begin{array}{l}E_{1}+E_{15}+E_{D} \\
=E_{10}+E_{14}\end{array}$ & $\frac{E_{1}-E_{10}}{E_{13}-E_{15}}$ \\
\hline Turbine & $E_{2}+W_{t}+E_{D}=E_{1}$ & $\frac{W_{t}}{E_{1}-E_{2}}$ \\
\hline Mixer & $E_{3}+E_{D}=E_{2}+E_{13}$ & $\frac{E_{3}}{E_{13}+E_{2}}$ \\
\hline LTRGN & $E_{4}+E_{7}+E_{D}=E_{3}+E_{6}$ & $\frac{E_{7}-E_{6}}{E_{3}-E_{4}}$ \\
\hline Condenser & $\begin{array}{l}E_{5}+E_{18}+E_{D} \\
=E_{17}+E_{4}\end{array}$ & $\frac{E_{18}-E_{17}}{E_{4}-E_{5}}$ \\
\hline HTRGN & $\begin{array}{l}E_{8}+E_{12}+E_{D} \\
=E_{7}+E_{11}\end{array}$ & $\frac{E_{8}-E_{7}}{E_{11}-E_{12}}$ \\
\hline Collector & $E_{14}+E_{D}=E_{16}+E_{\text {sun }}$ & $\frac{E_{14}-E_{16}}{E_{\text {solar }}}$ \\
\hline Pump & $E_{6}+E_{D}=E_{5}+W_{p}$ & $\frac{E_{6}-E_{5}}{W_{p}}$ \\
\hline
\end{tabular}
below where T_s is the thermodynamic average temperature.

$$
\dot{E}^{Q}=\dot{Q}\left(1-\frac{T_{0}}{T_{S}}\right)
$$

Based on the SPECO methodology, exergy destruction of each component is the difference between exergy of fuel and product of the component.

$$
\dot{E}_{D}=\dot{E}_{P}-\dot{E}_{F}
$$

Based on the above definitions, the exergy balance of each component is presented in Table 1.

Table 1. Exergy Analysis of the Solar Driven Kalina Cycle. 


\subsection{Emergy Analysis Equation}

In order to perform the emergy analysis on the proposed cycle, all input variables should be transformed into equivalent 'solar emergy joules' (SEJ). This transformation can be done by multiplying the input variable to its relevant unit emergy value (UEV) (or transformity). The amount of emergy used to produce a given amount of mass, energy and etc. is called unit emergy value or specifically transformity (when we are talking about energy). Unit emergy values of a vast majority of materials and different kinds of energies are published in different articles, but transformity values are usually presented in the quantity of energy-based emergy. As we are evaluating the system using exergy, we need to multiply these transformity values by a scale factor $(\beta)$ to produce exergy-based values [21]. This scale factor can be described as follows

$$
\beta=1+\frac{1}{3}\left(\frac{T_{0}}{T_{S}}\right)^{4}-\frac{4}{3}\left(\frac{T_{0}}{T_{S}}\right)
$$

where $\mathrm{T}_{\mathrm{S}}$ is the temperature of the sun and $\mathrm{T}_{0}$ is the reference point temperature.

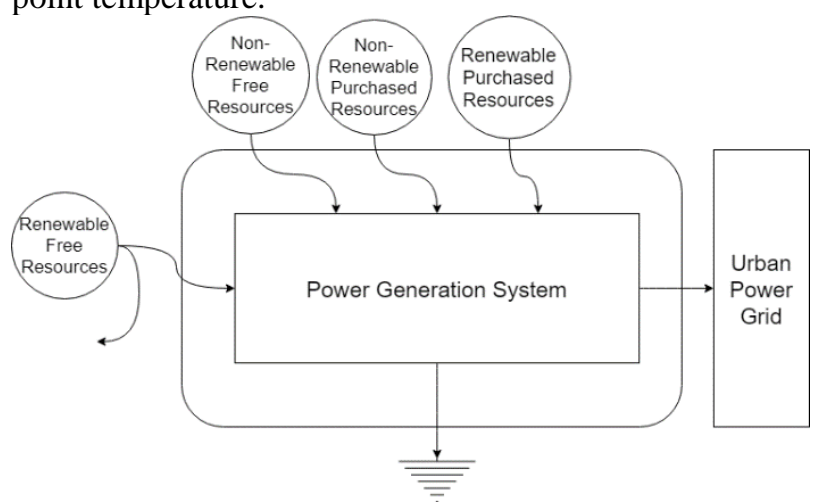

Figure 2. Boundary of the system.

Figure 2 shows the schematic of the boundary of the power generating cycle and input/output emergy flows of the system. Inputs of the system are divided into four categories: renewable purchased sources (RP), non-renewable purchased sources (NP), free renewable sources (R1), free non-renewable sources (NR). Based on the emergy inputs, five indices are defined to evaluate the performance of the cycle. The sum of all emergy inputs is called yield (Y) and can be calculated with Eq. (27):

$$
Y=R P+N P+R 1+N R
$$

The emergy yield ratio (EYR) is defined as below:

$$
E Y R=\frac{Y}{R P+N P}
$$

This parameter presents the ability of the cycle to exploit local resources [22]. The larger EIR means that the higher emergy (versus the invested emergy) is returned to the system. Environmental load ratio (ELR) is the ratio between non-renewable and renewable resources used in the system and can be calculated from the following equation:

$$
E L R=\frac{N R+N P}{R 1+R P}
$$

Emergy Sustainability Index (ESI) is the ratio of emergy yield ratio and environmental loading. This parameter can measure the ecological sustainability, impact on the local environment, and the society's profit [23, 24]. A system with ESI higher than 5 is called a sustainable system and if this index is lower than 1 , the system is not sustainable $[25,26]$.

$$
E S I=\frac{E Y R}{E L R}
$$

Finally, the Transformity of the cycle is defined as the amount of emergy used to produce the required electricity.

$$
\text { Transformity }=\frac{Y}{W_{\text {net }}}
$$

The purchased equipment cost and mass of components are estimated based on their operational parameters. The correlations from other researches ([17, 27-30]) are used to estimate the cost, mass, and composition of components (the required values for input emergy of the system are listed in Table 2). These input variables should be in the form of unit per time that can be used in EMergoeconomic and EMergoenvironmental analysis. The following equation is used for this manner:

$$
\dot{U}_{k}=\frac{P E C \times C R F \times \phi}{N \times 3600}
$$

Where $\phi$ is the maintenance factor and assumed to be $1.06, \mathrm{~N}$ presents the working hours of the plant in a year which is 7446 in this study. CRF is the capital recovery factor related to the system lifetime and interest year and can be

\begin{tabular}{|c|c|c|c|c|c|}
\hline Item & material & data & unit & transformity & emergy \\
\hline \multicolumn{6}{|c|}{ NP } \\
\hline \multirow[t]{2}{*}{ MXT } & Steel ${ }^{a}$ & $1.94 \mathrm{E}+05$ & $\mathrm{~g}$ & $3.79 \mathrm{E}+09$ & $7.37 \mathrm{E}+14$ \\
\hline & steel high alloy ${ }^{b}$ & $5.83 \mathrm{E}+05$ & $\mathrm{~g}$ & $4.87 \mathrm{E}+10$ & $2.84 \mathrm{E}+16$ \\
\hline \multirow[t]{2}{*}{ CFP } & Steel ${ }^{\text {a }}$ & $1.04 \mathrm{E}+04$ & g & $3.79 \mathrm{E}+09$ & $3.95 \mathrm{E}+13$ \\
\hline & cast iron ${ }^{a}$ & $1.93 \mathrm{E}+04$ & $\mathrm{~g}$ & $2.42 \mathrm{E}+09$ & $4.68 \mathrm{E}+13$ \\
\hline boiler & Steel $^{\mathrm{a}}$ & $1.07 \mathrm{E}+07$ & $\mathrm{~g}$ & $3.79 \mathrm{E}+09$ & $4.04 \mathrm{E}+16$ \\
\hline SEP & Steel $^{\mathrm{a}}$ & $5.50 \mathrm{E}+04$ & $\mathrm{~g}$ & $3.79 \mathrm{E}+09$ & $2.08 \mathrm{E}+14$ \\
\hline \multirow[t]{2}{*}{ SH } & Steel $^{\mathrm{a}}$ & $1.01 \mathrm{E}+05$ & $\mathrm{~g}$ & 3.79E+09 & $3.85 \mathrm{E}+14$ \\
\hline & steel low alloy ${ }^{b}$ & $3.04 \mathrm{E}+05$ & $\mathrm{~g}$ & $5.87 \mathrm{E}+09$ & $1.79 \mathrm{E}+15$ \\
\hline LTRGN & Steel $^{\mathrm{a}}$ & $3.04 \mathrm{E}+05$ & $\mathrm{~g}$ & $3.79 \mathrm{E}+09$ & $1.15 \mathrm{E}+15$ \\
\hline HTRGN & Steel $^{\mathrm{a}}$ & $1.06 \mathrm{E}+06$ & $\mathrm{~g}$ & 3.79E+09 & $4.02 \mathrm{E}+15$ \\
\hline \multirow[t]{2}{*}{ CND } & Steel ${ }^{a}$ & $1.74 \mathrm{E}+06$ & $\mathrm{~g}$ & $3.79 \mathrm{E}+09$ & $6.59 \mathrm{E}+15$ \\
\hline & steel low alloy ${ }^{b}$ & $5.22 \mathrm{E}+06$ & $\mathrm{~g}$ & $5.87 \mathrm{E}+09$ & $3.06 \mathrm{E}+16$ \\
\hline \multirow[t]{2}{*}{ COLL } & Steel $^{\text {a }}$ & $1.70 \mathrm{E}+08$ & $\mathrm{~g}$ & $3.79 \mathrm{E}+09$ & $6.46 \mathrm{E}+17$ \\
\hline & $\mathrm{R} 1$ & & & & \\
\hline \multirow[t]{2}{*}{ Q_Sun } & & $1.0722 \mathrm{E}+15$ & $\mathrm{~J}$ & 1 & $1.07 \mathrm{E}+15$ \\
\hline & $\mathrm{RP}$ & & & & \\
\hline Water & & $2.1444 \mathrm{E}+12$ & $\mathrm{~g}$ & 295000 & $6.33 \mathrm{E}+17$ \\
\hline \multicolumn{6}{|c|}{ Production } \\
\hline Electricity & & $4.0236 \mathrm{e}+13$ & $\mathrm{~J}$ & $3.46 \mathrm{E}+04$ & \\
\hline \multicolumn{6}{|c|}{ Purchased Equipment Cost } \\
\hline MXT & & 11952000 & $\$$ & $9.95 \mathrm{E}+11^{\mathrm{c}}$ & $1.19 \mathrm{E}+19$ \\
\hline CFP & & 1068300 & $\$$ & $9.95 \mathrm{E}+11^{\mathrm{c}}$ & $1.06 \mathrm{E}+18$ \\
\hline LTRGN & & 51391 & $\$$ & $9.95 \mathrm{E}+11^{\mathrm{c}}$ & $5.11 \mathrm{E}+16$ \\
\hline HTRGN & & 93327 & $\$$ & $9.95 \mathrm{E}+11^{\mathrm{c}}$ & $9.29 \mathrm{E}+16$ \\
\hline Boiler & & 159430 & $\$$ & $9.95 \mathrm{E}+11^{\mathrm{c}}$ & $1.59 \mathrm{E}+17$ \\
\hline SEP & & 8000 & $\$$ & $9.95 \mathrm{E}+11^{\mathrm{c}}$ & $7.96 \mathrm{E}+15$ \\
\hline SH & & 28869 & $\$$ & $9.95 \mathrm{E}+11^{\mathrm{c}}$ & $2.87 \mathrm{E}+16$ \\
\hline CND & & 95272 & $\$$ & $9.95 \mathrm{E}+11^{\mathrm{c}}$ & $9.48 \mathrm{E}+16$ \\
\hline COLL & & 724910 & $\$$ & $9.95 \mathrm{E}+11^{\mathrm{c}}$ & $7.21 \mathrm{E}+17$ \\
\hline
\end{tabular}
calculated from the following equation:

$$
C R F=\frac{i(1+i)^{n}}{(1+i)^{n}-1}
$$

The Lifetime of the system (n) assumed to be 20 years and interest rate (i) is $10 \%$.

Table 2. Input Variables of the System. 


\subsubsection{EMergoeconomic Analysis}

The principles of EMergoeconomic analysis is similar to conventional exergoeconomic analysis. The Specific Exergy Costing (SPECO) [31] method is used to evaluate the monetary emergy values of all exergy flows. First, a monetary emergy rate $\mathrm{M}_{-}^{*} \mathrm{i}$ is defined as below:

$$
\dot{M}_{i}=m_{i} \dot{E}_{i}
$$

In which, the monetary emergy per unit exergy is represented by $\mathrm{m} \_\mathrm{i}$ and monetary emergy rate $\left(\mathrm{M}_{-}{ }^{-} \mathrm{i}\right)$ is represented in the quantity of sej per unit time. The monetary balance of each component can be written as follows:

$$
\dot{M}_{P . k}=\dot{M}_{F . k}+\dot{U}_{k}
$$

In Eq. (35), monetary-based emergy rate of product and fuel streams are represented by $\dot{M}_{\text {P.k }}$ and $\dot{M}_{\text {F.k }}$ and $\dot{U}_{\mathrm{k}}$ is the monetary emergy rate of component $\mathrm{k}$ :

$$
\dot{U}_{k}=\dot{U}_{k}^{C I}+\dot{U}_{k}^{O M}
$$

In Eq. (36), $\dot{U}_{\mathrm{k}}^{\mathrm{CI}}$ and $\dot{U}_{\mathrm{k}}^{\mathrm{OM}}$ are the capital investment and operation-maintenance cost of plant in the form of monetary emergy rate, respectively. To calculate fuel and product's specific monetary value, the following equations can be used:

$$
\begin{aligned}
& m_{P . k}=\frac{\dot{M}_{P . k}}{\dot{E}_{P . k}} \\
& m_{F . k}=\frac{\dot{M}_{F . k}}{\dot{E}_{F . k}}
\end{aligned}
$$

and the destruction rate of monetary emergy is calculated from the following equation:

$$
\dot{M}_{D . k}=m_{F . k} \dot{E}_{D . k}
$$

Total emergy rate of a component can be calculated by the sum of its emergy destruction rate and monetary as below:

$$
\dot{M}_{T O T . k}=\dot{U}_{k}+\dot{M}_{D . k}
$$

The EMergoeconomic factor of each component can be

\begin{tabular}{|c|c|c|}
\hline Component & EMergoeconomic balance & Auxiliary quation \\
\hline Boiler & $\begin{array}{c}m_{9} E_{9}+m_{16} E_{16}=m_{8} E_{8}+m_{15} E_{15} \\
+\dot{U}_{\text {boiler }}\end{array}$ & $\begin{array}{l}m 16=m 15 \\
m_{10}-m_{9}\end{array}$ \\
\hline Separator & $m_{10} E_{10}+m_{11} E_{11}=m_{9} E_{9}+\dot{U}_{s e p}$ & $\begin{array}{l}\overline{E_{10}-E 9} \\
=\frac{m_{11}-m_{9}}{E_{11}-E_{9}}\end{array}$ \\
\hline Superheater & $\begin{aligned} m_{1} E_{1}+m_{15} E_{15}= & m_{10} E_{10} \\
& +m_{14} E_{14} \\
& +\dot{U}_{s h}\end{aligned}$ & $m_{15}=m_{14}$ \\
\hline $\begin{array}{l}\text { Turbine } \\
\text { Mixer }\end{array}$ & $\begin{array}{l}m_{2} E_{2}+m_{W_{t}} W_{t}=m_{1} E_{1}+\dot{U}_{t} \\
m_{3} E_{3}=m_{2} E_{2}+m_{13} E_{13}+\dot{U}_{m x r}\end{array}$ & $m_{2}=m_{1}$ \\
\hline LTRGN & $\begin{array}{r}m_{4} E_{4}+m_{7} E_{7}=m_{3} E_{3}+m_{6} E_{6} \\
+\dot{U}_{\text {ltrgn }}\end{array}$ & $m_{3}=m_{4}$ \\
\hline Condenser & $\begin{array}{c}m_{5} E_{5}+m_{18} E_{18}=m_{4} E_{4}+m_{17} E_{17} \\
+\dot{U}_{c n d}\end{array}$ & $m_{18}=m_{17}=0$ \\
\hline HTRGN & $\begin{aligned} m_{8} E_{8}+m_{12} E_{12}= & m_{7} E_{7}+m_{11} E_{11} \\
& +\dot{U}_{\text {htrgn }}\end{aligned}$ & $m_{12}=m_{11}$ \\
\hline Collector & $\begin{array}{r}m_{14} E_{14}=m_{16} E_{16}+m_{\text {sun }} E_{\text {sun }} \\
+ \\
+\dot{U}_{\text {coll }}\end{array}$ & $m_{\text {sun }}=0$ \\
\hline Pump & $m_{6} E_{6}=m_{5} E_{5}+m_{W_{p}} W_{p}+\dot{U}_{p}$ & $m_{W_{p}}=m_{W_{t}}$ \\
\hline
\end{tabular}
calculated as follows:

$$
f_{m . k}=\frac{\dot{U}_{k}}{\dot{U}_{k}+\dot{M}_{D . k}} \times 100=\frac{\dot{U}_{k}}{\dot{M}_{\text {TOT.k }}} \times 100
$$

Based on the above definitions, the EMergoeconomic balance of each component is presented in Table 3 .

Table 3. EMergoeconomic Balance.

\subsubsection{EMergoenvironmental Analysis}

Similar to exergoenvironmental analysis, the EMergoenvironmenal analysis is performed by applying the ecological emergy values to exergy flows. Ecological emergy rate can be expressed by multiplying the specific ecological emergy of a stream $\left(n_{i}\right)$ to exergy rate of this stream:

$$
\dot{N}_{i}=n_{i} \dot{E}_{i}
$$

The ecological emergy balance of each component can be presented as follows:

$$
\dot{N}_{P . k}=\dot{N}_{F . k}+\dot{V}_{k}
$$

Where $\dot{V}_{k}$ is the sum of emergy rate in the construction phase $\left(\dot{V}_{k}^{C O}\right)$, operation-maintenance $\left(\dot{V}_{k}^{O M}\right)$, and disposal of the component $\left(\dot{V}_{k}^{D I}\right)$.

$$
\dot{V}_{k}=\dot{V}_{k}^{C O}+\dot{V}_{k}^{O M}+\dot{V}_{k}^{D I}
$$

By EMergoenvironmental balance equations, the specific emergy of product and fuel in the ecological analysis can be described as follows:

$$
\begin{aligned}
& n_{P . k}=\frac{\dot{N}_{P . k}}{\dot{E}_{P . k}} \\
& n_{F . k}=\frac{\dot{N}_{F . k}}{\dot{E}_{F . k}}
\end{aligned}
$$

And the destruction rate of ecological emergy is calculated from the following equation:

$$
\dot{N}_{D . k}=n_{F . k} \dot{E}_{D . k}
$$

\begin{tabular}{|c|c|c|}
\hline Component & EMergoenvironmental balance & Auxiliary equation \\
\hline Boiler & $\begin{array}{r}n_{9} E_{9}+n_{16} E_{16}=n_{8} E_{8}+n_{15} E_{15} \\
+\dot{V}_{\text {boiler }}\end{array}$ & $n_{16}=n_{15}$ \\
\hline Separator & $n_{10} E_{10}+n_{11} E_{11}=n_{9} E_{9}+\dot{V}_{s e p}$ & $\frac{n_{10}-n_{9}}{E_{10}-E 9}=\frac{n_{11}-n_{9}}{E_{11}-E_{9}}$ \\
\hline Super heater & $\begin{aligned} n_{1} E_{1}+n_{15} E_{15}=n_{10} & E_{10} \\
& +n_{14} E_{14} \\
& +\dot{V}_{s h}\end{aligned}$ & $n_{15}=n_{14}$ \\
\hline $\begin{array}{l}\text { Turbine } \\
\text { Mixer }\end{array}$ & $\begin{array}{l}n_{2} E_{2}+n_{W_{t}} W_{t}=n_{1} E_{1}+\dot{V}_{t} \\
n_{3} E_{3}=n_{2} E_{2}+n_{13} E_{13}+\dot{V}_{m x r}\end{array}$ & $n_{2}=n_{1}$ \\
\hline LTRGN & $\begin{aligned} n_{4} E_{4}+n_{7} E_{7}=n_{3} E_{3} & +n_{6} E_{6} \\
& +\dot{V}_{\text {ltrgn }}\end{aligned}$ & $n_{3}=n_{4}$ \\
\hline Condenser & $\begin{aligned} n E_{5}+n_{18} E_{18}=n_{4} E_{4} & +n_{17} E_{17} \\
& +\dot{V}_{\text {cnd }}\end{aligned}$ & $n_{18}=n_{17}=6.86 \times 10^{3} \mathrm{a}$ \\
\hline HTRGN & $\begin{aligned} n_{8} E_{8}+n_{12} E_{12}=n_{7} E_{7} & +n_{11} E_{11} \\
& +\dot{V}_{h t r g n}\end{aligned}$ & $n_{12}=n_{11}$ \\
\hline Collector & $\begin{array}{r}n_{14} E_{14}=n_{16} E_{16}+n_{\text {sun }} E_{\text {sun }} \\
+V_{\text {coll }}\end{array}$ & $m_{\text {sun }}=1$ \\
\hline Pump & $n_{6} E_{6}=n_{5} E_{5}+n_{W_{p}} W_{p}+\dot{V}_{p}$ & $n_{W_{p}}=n_{W_{t}}$ \\
\hline
\end{tabular}

Total emergy rate of a component in the ecological analysis can be calculated by the sum of its destruction rate and it's component related monetary emergy as below:

$$
\dot{N}_{\text {TOT.k }}=\dot{V}_{k}+\dot{N}_{D . k}
$$

The EMergoenvironmental factor for each component is calculated from the following equation:

$$
f_{m . k}=\frac{\dot{V}_{k}}{\dot{V}_{k}+\dot{N}_{D . k}} \times 100=\frac{\dot{V}_{k}}{\dot{N}_{\text {TOT.k }}} \times 100
$$

The EMergoeconomic balance of each component is presented in Table 4 .

Table 4. EMergoenvironmental Balance.

a: obtained from [33]

Based on the above definitions, the overall performance of the power plant in EMergoeconomic and EMergoenvironmental analysis can be described as follows: 


$$
\begin{aligned}
& \psi_{\text {м.тот }}= \frac{\text { Outlet Monetary Emergy }}{\text { Inlet Monetary Emergy }} \\
& \psi_{\text {N.тот }}=\frac{\text { Outlet Ecological Emergy }}{\text { Inlet Ecological Emergy }}
\end{aligned}
$$

\section{Results and Discussion}

Results of thermodynamic analysis and properties of each stream are shown in Table 5. The results show that the plant generates $75.05 \mathrm{~kW}$ output power with the thermal efficiency of $10.62 \%$.

Table 5. Thermodynamic Properties of Streams in the Solar Driven Kalina Cycle.

\begin{tabular}{cccccc}
\hline stream & $\begin{array}{c}\text { ammonia } \\
\text { concentration }\end{array}$ & $\begin{array}{c}\text { pressure } \\
(\mathrm{kPa})\end{array}$ & temperature $(\mathrm{C})$ & $\begin{array}{c}\text { mass flow } \\
(\mathrm{kg} / \mathrm{s})\end{array}$ & $\begin{array}{c}\text { Total } \\
\text { exergy } \\
(\mathrm{kW})\end{array}$ \\
\hline 1 & 0.95 & 3560 & 135.00 & 0.47 & 391.45 \\
2 & 0.95 & 750 & 68.75 & 0.47 & 306.04 \\
3 & 0.7 & 750 & 47.84 & 1.00 & 538.61 \\
4 & 0.7 & 750 & 44.45 & 1.00 & 534.33 \\
5 & 0.7 & 750 & 29.24 & 1.00 & 517.91 \\
6 & 0.7 & 3560 & 29.89 & 1.00 & 521.75 \\
7 & 0.7 & 3560 & 42.68 & 1.00 & 523.98 \\
8 & 0.7 & 3560 & 82.23 & 1.00 & 545.72 \\
9 & 0.7 & 3560 & 125.00 & 1.00 & 688.22 \\
10 & 0.95 & 3560 & 125.00 & 0.47 & 365.92 \\
11 & 0.47 & 3560 & 125.00 & 0.53 & 305.71 \\
12 & 0.47 & 3560 & 49.60 & 0.53 & 272.21 \\
13 & 0.47 & 750 & 50.05 & 0.53 & 270.51 \\
14 & - & - & 145.00 & 3.53 & 4019.36 \\
15 & - & - & 139.25 & 3.53 & 3955.20 \\
16 & - & - & 97.23 & 3.53 & 3475.99 \\
\hline
\end{tabular}

Exergetic efficiency and exergy destruction of each component are presented in Figure 3 and Figure 4. Results show that the boiler and superheater have the most exergy destruction $(68.8 \%$ and $7.9 \%$ of the total exergy destruction, respectively) and the lowest exergetic efficiency (29.7\% and $39.8 \%$, respectively). The lowest exergetic efficiency in boiler shows that the boiler is the most prior component in order to improve the performance of the cycle from exergy analysis.

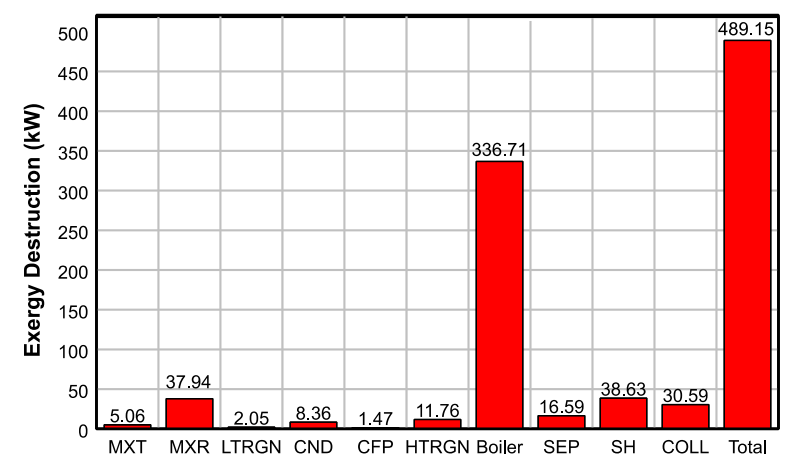

Figure 3. Exergy destruction of cycle's components.

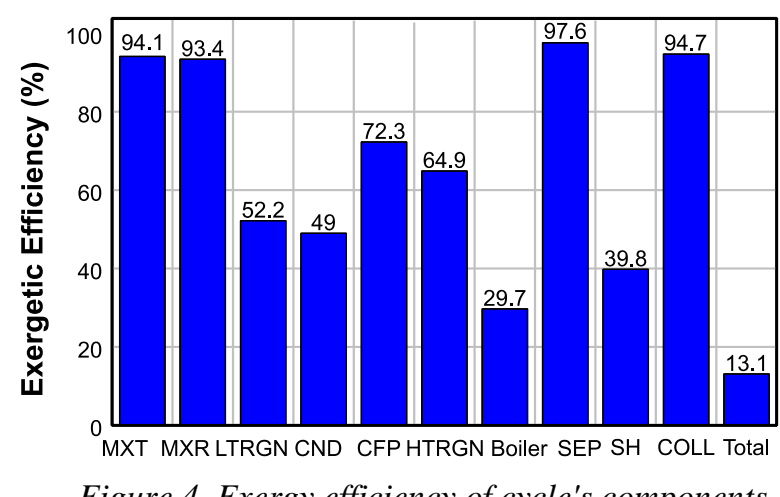

Results of EMergoeconomic analysis are summarized in Table 6. Results show that the turbine has the highest total monetary emergy rate. This component has low monetary emergy, but the emergy destruction in this component is high and thus the turbine has the highest total monetary emergy rate. Therefore, improving this component can improve the monetary performance of the cycle.

Table 6. Results of Monetary Analysis of the Proposed Cycle.

\begin{tabular}{ccccccc}
\hline \multicolumn{8}{c}{ Cycle. } \\
\hline component & $\begin{array}{c}\dot{U}_{k} \\
(\mathrm{sej} / \mathrm{h})\end{array}$ & $\begin{array}{c}\dot{M}_{D} \\
(\mathrm{sej} / \mathrm{h})\end{array}$ & $\dot{U}+\dot{M}_{D}$ & $\begin{array}{c}m_{F} \\
(\mathrm{sej} / \mathrm{GJ})\end{array}$ & $m_{P}(\mathrm{sej} / \mathrm{GJ})$ & $\begin{array}{c}f_{m} \\
(\%)\end{array}$ \\
\hline MXT & $1.99 \mathrm{E}+14$ & $3.11 \mathrm{E}+12$ & $2.02 \mathrm{E}+14$ & $1.71 \mathrm{E}+14$ & $8.69 \mathrm{E}+14$ & 98.46 \\
MXR & $0.00 \mathrm{E}+00$ & $2.41 \mathrm{E}+13$ & $2.41 \mathrm{E}+13$ & $1.76 \mathrm{E}+14$ & $1.89 \mathrm{E}+14$ & 0.00 \\
LTRGN & $8.55 \mathrm{E}+11$ & $1.39 \mathrm{E}+12$ & $2.24 \mathrm{E}+12$ & $1.89 \mathrm{E}+14$ & $4.68 \mathrm{E}+14$ & 38.09 \\
CND & $1.59 \mathrm{E}+12$ & $5.68 \mathrm{E}+12$ & $7.26 \mathrm{E}+12$ & $1.89 \mathrm{E}+14$ & - & 21.82 \\
CFP & $1.78 \mathrm{E}+13$ & $4.59 \mathrm{E}+12$ & $2.24 \mathrm{E}+13$ & $8.69 \mathrm{E}+14$ & $3.41 \mathrm{E}+15$ & 79.47 \\
HTRGN & $1.55 \mathrm{E}+12$ & $7.71 \mathrm{E}+12$ & $9.26 \mathrm{E}+12$ & $1.82 \mathrm{E}+14$ & $3.01 \mathrm{E}+14$ & 16.76 \\
Boiler & $2.65 \mathrm{E}+12$ & $7.47 \mathrm{E}+12$ & $1.01 \mathrm{E}+13$ & $6.17 \mathrm{E}+12$ & $2.59 \mathrm{E}+13$ & 26.19 \\
SEP & $1.33 \mathrm{E}+11$ & $1.06 \mathrm{E}+13$ & $1.07 \mathrm{E}+13$ & $1.77 \mathrm{E}+14$ & $1.82 \mathrm{E}+14$ & 1.24 \\
SH & $4.80 \mathrm{E}+11$ & $8.58 \mathrm{E}+11$ & $1.34 \mathrm{E}+12$ & $6.17 \mathrm{E}+12$ & $2.07 \mathrm{E}+13$ & 35.90 \\
COLL & $1.21 \mathrm{E}+13$ & $0.00 \mathrm{E}+00$ & $1.21 \mathrm{E}+13$ & $0.00 \mathrm{E}+00$ & $4.56 \mathrm{E}+13$ & 100.00 \\
\hline
\end{tabular}

Table 7 shows the results of EMergoenvironmental analysis. Table 7 shows that the mixer and separator have the highest emergy destruction and total ecological emergy rate. Thus, for improving the ecological performance of the cycle these components should be improved.

Table 7. Results of Ecological Analysis of the Proposed Cycle.

\begin{tabular}{ccccccc}
\hline component & $\begin{array}{c}\dot{V}_{k} \\
(\mathrm{sej} / \mathrm{h})\end{array}$ & $\begin{array}{c}\dot{N}_{D} \\
(\mathrm{sej} / \mathrm{h})\end{array}$ & $\dot{V}+\dot{N}_{D}$ & $\begin{array}{c}n_{F} \\
(\mathrm{sej} / \mathrm{GJ})\end{array}$ & $\begin{array}{c}n_{P} \\
(\mathrm{sej} / \mathrm{GJ})\end{array}$ & $\begin{array}{c}f_{m} \\
(\%)\end{array}$ \\
\hline MXT & $2.44 \mathrm{E}+10$ & $4.51 \mathrm{E}+12$ & $4.53 \mathrm{E}+12$ & $2.48 \mathrm{E}+14$ & $2.63 \mathrm{E}+14$ & 0.54 \\
MXR & $0.00 \mathrm{E}+00$ & $3.50 \mathrm{E}+13$ & $3.50 \mathrm{E}+13$ & $2.56 \mathrm{E}+14$ & $2.74 \mathrm{E}+14$ & 0.00 \\
LTRGN & $9.62 \mathrm{E}+08$ & $2.02 \mathrm{E}+12$ & $2.02 \mathrm{E}+12$ & $2.74 \mathrm{E}+14$ & $5.26 \mathrm{E}+14$ & 0.05 \\
CND & $3.11 \mathrm{E}+10$ & $8.26 \mathrm{E}+12$ & $8.29 \mathrm{E}+12$ & $2.74 \mathrm{E}+14$ & $0.00 \mathrm{E}+00$ & 0.38 \\
CFP & $7.21 \mathrm{E}+07$ & $1.39 \mathrm{E}+12$ & $1.39 \mathrm{E}+12$ & $2.63 \mathrm{E}+14$ & $6.77 \mathrm{E}+15$ & 0.01 \\
HTRGN & $3.36 \mathrm{E}+09$ & $1.13 \mathrm{E}+13$ & $1.13 \mathrm{E}+13$ & $2.66 \mathrm{E}+14$ & $4.10 \mathrm{E}+14$ & 0.03 \\
Boiler & $3.38 \mathrm{E}+10$ & $3.36 \mathrm{E}+11$ & $3.70 \mathrm{E}+11$ & $2.77 \mathrm{E}+11$ & $9.98 \mathrm{E}+11$ & 9.14 \\
SEP & $1.74 \mathrm{E}+08$ & $1.55 \mathrm{E}+13$ & $1.55 \mathrm{E}+13$ & $2.59 \mathrm{E}+14$ & $2.66 \mathrm{E}+14$ & 0.00 \\
SH & $1.82 \mathrm{E}+09$ & $3.85 \mathrm{E}+10$ & $4.04 \mathrm{E}+10$ & $2.77 \mathrm{E}+11$ & $7.16 \mathrm{E}+11$ & 4.50 \\
COLL & $5.40 \mathrm{E}+11$ & $1.10 \mathrm{E}+08$ & $5.40 \mathrm{E}+11$ & $1.00 \mathrm{E}+09$ & $2.04 \mathrm{E}+12$ & 99.98 \\
\hline
\end{tabular}


Figure 5 and Figure 6 illustrate monetary and ecological emergy values of streams of the cycle. Results show that the ecological emergy of streams is higher than their monetary emergy because of higher ecological emergy of input streams.

Base on the governed results, in all components (Except turbine) the monetary and ecological emergy rate is avoidable compared to different streams. Also, the streams that enter from collector to considered cycle has a greater impact on the monetary performance of the cycle (compared to ecological impact).

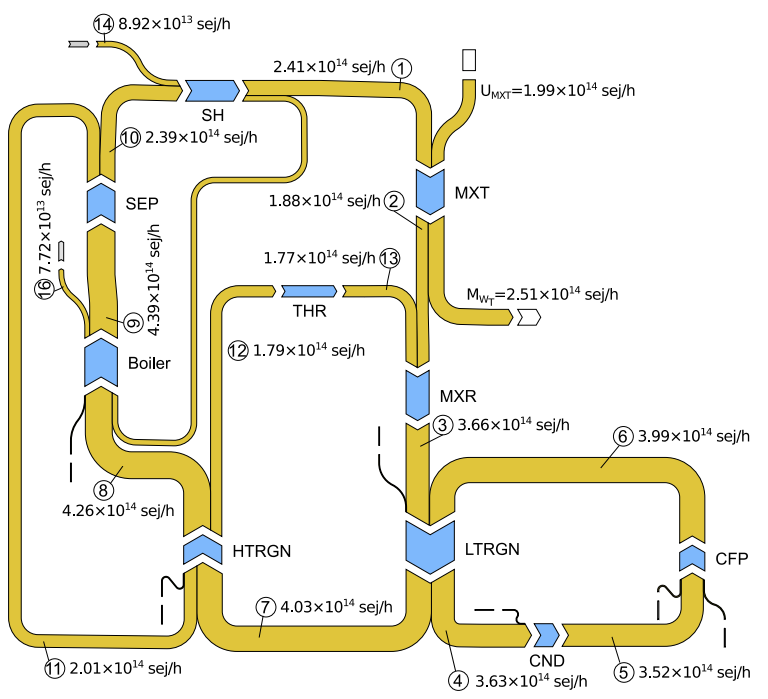

Figure 5. Sankey diagram of the EMergoeconomic analysis.

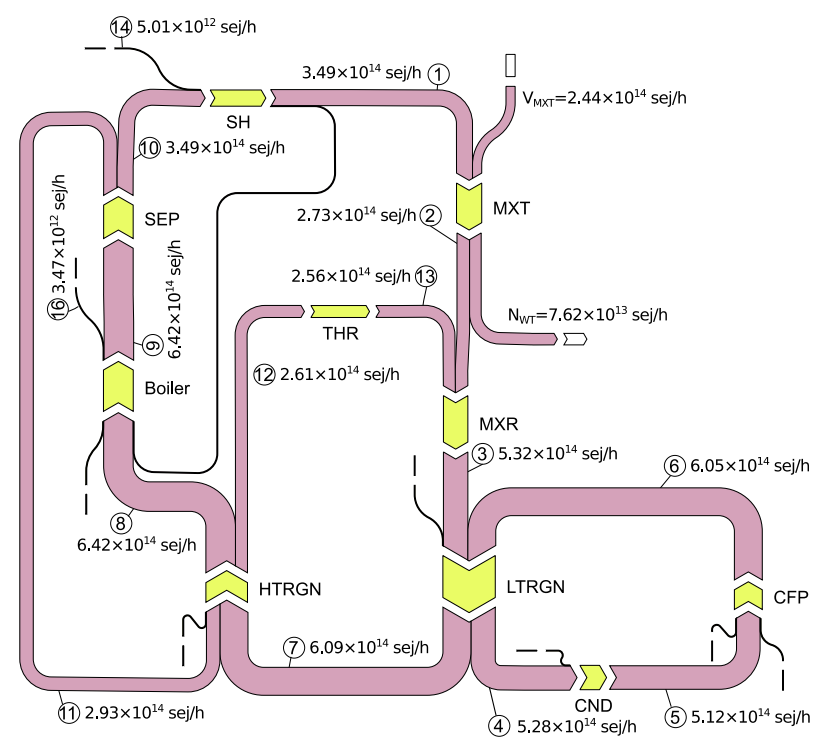

Figure 6. Sankey diagram of EMergoenvironmental analysis.

Table 8 shows the comparison between the emergy indicators in the current study and other referenced power plants. Results show that the transformity (amount of emergy needed for producing 1 joule of electricity) in the current system $(3.46 \mathrm{E}+04)$ is lower than other considered renewable power plants. In the considered solar-powered Kalina cycle a large percentage of inputs emergies have been purchased and the invested emergy has a greater portion of input emergy flows (compared to free resources emergy), thus the EYR index is equal to 1.00. Environmental loading ratio (the ratio between non-renewable inputs to renewable ones) and of the proposed cycle emergy sustainability index are 1.2 and 0.83 , respectively. Results show that the ESI in the consider power plant is lower than other renewable power plant and is higher than the fossil power plant.

Table 8. Solar Driven Kalina and Eight Other Power Plants Emergy Indicators.

\begin{tabular}{cccccc}
\hline & Transformity & EYR & ELR & ESI & Reference \\
\hline Solar-driven Kalina & $3.46 \mathrm{E}+04$ & 1.00 & 1.20 & 0.83 & $\begin{array}{c}\text { current } \\
\text { study }\end{array}$ \\
Wind & $5.89 \mathrm{E}+04$ & 7.47 & 0.15 & 48.30 & {$[16]$} \\
Geothermal & $1.42 \mathrm{E}+05$ & 4.81 & 0.44 & 11.05 & {$[16]$} \\
Hydro & $5.87 \mathrm{E}+04$ & 7.65 & 0.45 & 16.90 & {$[16]$} \\
Methane & $1.60 \mathrm{E}+04$ & 6.60 & 11.78 & 0.56 & {$[16]$} \\
Oil & $1.87 \mathrm{E}+05$ & 4.21 & 14.24 & 0.30 & {$[16]$} \\
Coal & $1.62 \mathrm{E}+05$ & 5.48 & 10.37 & 0.53 & {$[16]$} \\
PV & $1.45 \mathrm{E}+05$ & 2.20 & - & - & {$[34]$} \\
CSP & $6.59 \mathrm{E}+04$ & 5.06 & 0.39 & 13.10 & {$[18]$} \\
\hline
\end{tabular}

The comparison of solar transformities in the proposed solar-driven Kalina cycle and other power plants are shown in Figure 7. Although the exergetic efficiency of the Kalina cycle is lower than a concentrated solar powered steam power plant; but because of lower input emergies (related to different component) compared to a steam cycle, the calculated transformity of the current cycle is lower than the steam power plant.

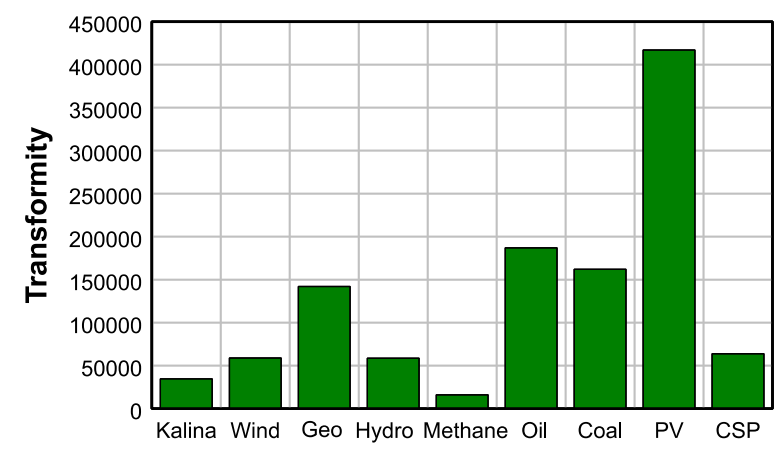

Figure 7. Transformities of a solar-driven kalina cycle compared to different power plants.

\section{Conclusions}

In this paper, the small solar-driven Kalina distributed power system is analyzed based on Emergy, Exergy, Economic and Environmental principles. The analysis process consists of thermodynamic analysis, exergy analysis, weight estimation, purchase cost estimation, emergy calculation and emergy balances. In the final step, the suitable exergy and emergy evaluation parameters are calculated for the evaluation process. The results of exergy analysis show that the boiler and super heater have the main role in the irreversibility of the current system and these should be improved. The results of EMergoeconomic show that for improvement in performance of the cycle the turbine and mixture should be modified. Comparison of the proposed solar-driven Kalina cycle with other referenced renewable and fossil power plant show that the current system operates in a suitable zone and has suitable characteristics and the transformity factor in the considered system is lower than the steam power plant. 


$\begin{array}{ll}\text { Nomenclature } \\ \dot{E} & \text { Exergy flow rate } \\ f_{m} & \text { EMergoeconomic factor } \\ f_{n} & \text { EMergoenvironmental factor } \\ \text { Y } & \text { Total emergy of outputs } \\ \text { RP } & \text { Renewable purchased emergy } \\ \text { NP } & \text { Non-renewable purchased emergy } \\ \text { R1 } & \text { Free renewable emergy } \\ \text { NR } & \text { Free non-renewable emergy } \\ \text { m } & \text { Specific monetary emergy } \\ \dot{M} & \text { Monetary emergy rate } \\ \text { n } & \text { Specific ecological emergy } \\ \dot{N} & \text { Ecological emergy rate } \\ r_{m} & \text { Relative monetary emergy difference } \\ r_{n} & \text { Relative ecological emergy difference } \\ \dot{U} & \text { Component monetary emergy rate } \\ \dot{V} & \text { Component ecological emergy rate } \\ \text { PEC } & \text { Process equipment cost } \\ \text { i } & \text { interest rate } \\ \text { Sej } & \text { Solar energy joules } \\ \beta & \text { Scale factor } \\ \text { h } & \text { Specific enthalpy } \\ \text { s } & \text { Specific entropy } \\ \text { MXT } & \text { Mixture turbine } \\ \text { MXR } & \text { Mixer } \\ \text { RGN } & \text { Regenerator } \\ \text { CND } & \text { Condenser } \\ \text { THR } & \text { Throttle } \\ \text { SEP } & \text { Separator } \\ \text { SH } & \text { Superheater } \\ \text { CFP } & \text { Condensate pump } \\ \text { Subscripts and superscripts } \\ \text { F } & \text { Fuel } \\ \text { P } & \quad \text { Product } \\ \text { D } & \quad \text { Destruction } \\ \text { PH } & \quad \text { Physical } \\ \text { CH } & \quad \text { Chemical } \\ & \end{array}$

\section{References:}

[1] A. I. Kalina, "Generation of energy by means of a working fluid, and regeneration of a working fluid," ed: Google Patents, 1982.

[2] E. Rogdakis, K. Antonopoulos, "A high efficiency NH3/H2O absorption power cycle," Heat Recovery Systems and CHP, 11, 263-275, 1991.

[3] H. M. Hettiarachchi, M. Golubovic, W. M. Worek, Y. Ikegami, "The performance of the Kalina cycle system 11 (KCS-11) with low-temperature heat sources," Journal of Energy Resources Technology, 129, 243-247, 2007.

[4] R. Murugan, P. Subbarao, "Thermodynamic analysis of Rankine-Kalina combined cycle," Int. J. Thermodynamics, 11, 133-141, 2008.

[5] P. Lolos, E. Rogdakis, "A Kalina power cycle driven by renewable energy sources," Energy, 34, 457-464, 2009.

[6] F. Sun, Y. Ikegami, B. Jia, "A study on Kalina solar system with an auxiliary superheater," Renewable Energy, 41, 210-219, 2012.

[7] N. S. Ganesh,T. Srinivas, "Design and modeling of low temperature solar thermal power station," Applied Energy, 91, 180-186, 2012.
[8] J. Wang, Z. Yan, E. Zhou, Y. Dai, "Parametric analysis and optimization of a Kalina cycle driven by solar energy," Applied Thermal Engineering, 50, 408-415, 2013.

[9] S. Peng, H. Hong, H. Jin, "Triple cycle for solar thermal power system adapted to periods with varying insolation," Energy, 60, 129-138, 2013.

[10] A. Modi, F. Haglind, "Performance analysis of a Kalina cycle for a central receiver solar thermal power plant with direct steam generation," Applied Thermal Engineering, 65, 201-208, 2014.

[11] F. Sun, W. Zhou, Y. Ikegami, K. Nakagami, X. Su, "Energy-exergy analysis and optimization of the solarboosted Kalina cycle system 11 (KCS-11)," Renewable Energy, 66, 268-279, 2014.

[12] V. Zare, S. Mahmoudi, M. Yari, "On the exergoeconomic assessment of employing Kalina cycle for GT-MHR waste heat utilization," Energy Conversion and Management, 90, 364-374, 2015.

[13] C. E. C. Rodríguez, J. C. E. Palacio, O. J. Venturini, E. E. S. Lora, V. M. Cobas, D. M. dos Santos, F. R. L. Dotto, V. Gialluca, "Exergetic and economic comparison of ORC and Kalina cycle for low temperature enhanced geothermal system in Brazil," Applied Thermal Engineering, 52, 109-119, 2013.

[14] F. A. Boyaghchi, M. Sabaghian, "Multi objective optimisation of a Kalina power cycle integrated with parabolic trough solar collectors based on exergy and exergoeconomic concept," International Journal of Energy Technology and Policy, 12, 154-180, 2016.

[15] B. Reza, R. Sadiq, K. Hewage, "Emergy-based life cycle assessment (Em-LCA) for sustainability appraisal of infrastructure systems: a case study on paved roads," Clean Technologies and Environmental Policy, 16, 251266, 2014.

[16] M. T. Brown, S. Ulgiati, "Emergy evaluations and environmental loading of electricity production systems," Journal of Cleaner Production, 10, 321-334, 2002 .

[17] H. Zhang, X. Guan, Y. Ding, C. Liu, "Emergy analysis of Organic Rankine Cycle (ORC) for waste heat power generation," Journal of Cleaner Production, 183, 1207 1215, 2018.

[18] M. Zhang, Z. Wang, C. Xu, H. Jiang, "Embodied energy and emergy analyses of a concentrating solar power (CSP) system," Energy Policy, 42, 232-238, 2012.

[19] S. Sha, M. Hurme, "Emergy evaluation of combined heat and power plant processes," Applied Thermal Engineering, 43, 67-74, 2012.

[20] M. Aghbashlo, M. A. Rosen, "Consolidating exergoeconomic and exergoenvironmental analyses using the emergy concept for better understanding energy conversion systems," Journal of Cleaner Production, 172, 696-708, 2018.

[21] S. Bastianoni, A. Facchini, L. Susani, E. Tiezzi, "Emergy as a function of exergy," Energy, 32, 11581162, 2007. 
[22] Y. Geng, P. Zhang, S. Ulgiati, J. Sarkis, "Emergy analysis of an industrial park: the case of Dalian, China," Science of the Total Environment, 408, 5273-5283, 2010.

[23] M. Brown, S. Ulgiati, "Emergy-based indices and ratios to evaluate sustainability: monitoring economies and technology toward environmentally sound innovation," Ecological Engineering, 9, 51-69, 1997.

[24] H. Pan, Y. Geng, P. Jiang, H. Dong, L. Sun, R. Wu, "An emergy based sustainability evaluation on a combined landfill and LFG power generation system," Energy, 143, 310-322, 2018.

[25] K. Cao, X. Feng, "Distribution of emergy indices and its application," Energy \& Fuels, 21, 1717-1723, 2007.

[26] S. Chen, B. Chen, "Sustainability and future alternatives of biogas-linked agrosystem (BLAS) in China: an emergy synthesis," Renewable and Sustainable Energy Reviews, 16, 3948-3959, 2012.

[27] R. Smith, Chemical process: design and integration, John Wiley \& Sons, 2005.

[28] D. Purevsuren, Thermoeconomic analysis of a new geothermal utilization CHP plant in Tsetserleg, Mongolia, United Nations University, 2005.
[29] C. Zhou, E. Doroodchi, B. Moghtaderi, "An in-depth assessment of hybrid solar-geothermal power generation," Energy Conversion and Management, 74, 88-101, 2013.

[30] E. J. C. Cavalcanti, "Exergoeconomic and exergoenvironmental analyses of an integrated solar combined cycle system," Renewable and Sustainable Energy Reviews, 67, 507-519, 2017.

[31] A. Lazzaretto, G. Tsatsaronis, "SPECO: a systematic and general methodology for calculating efficiencies and costs in thermal systems," Energy, 31, 1257-1289, 2006.

[32] F. M. Pulselli, N. Patrizi, S. Focardi, "Calculation of the unit emergy value of water in an Italian watershed," Ecological Modelling, 222, 2929-2938, 2011.

[33] A. Baral, B. R. Bakshi, "Emergy analysis using US economic input-output models with applications to life cycles of gasoline and corn ethanol," Ecological Modelling, 221, 1807-1818, 2010.

[34] M. T. Brown, M. Raugei, S. Ulgiati, "On boundaries and 'investments' in emergy synthesis and LCA: a case study on thermal vs. photovoltaic electricity," Ecological Indicators, 15, 227-235, 2012. 